\title{
RESEARCH
}

Open Access

\section{Roads constrain movement across behavioural processes in a partially migratory ungulate}

Gioele Passoni ${ }^{1,2^{*}}$, Tim Coulson ${ }^{1}$, Nathan Ranc ${ }^{3}$, Andrea Corradini ${ }^{2,4,5}$, A. J. Mark Hewison ${ }^{6,7}$, Simone Ciuti ${ }^{8}$, Benedikt Gehr ${ }^{9}$, Marco Heurich ${ }^{10,11,12}$, Falko Brieger ${ }^{13}$, Robin Sandfort ${ }^{14}$, Atle Mysterud ${ }^{15}$, Niko Balkenhol ${ }^{16}$ and Francesca Cagnacci ${ }^{2}$

\begin{abstract}
Background: Human disturbance alters animal movement globally and infrastructure, such as roads, can act as physical barriers that impact behaviour across multiple spatial scales. In ungulates, roads can particularly hamper key ecological processes such as dispersal and migration, which ensure functional connectivity among populations, and may be particularly important for population performance in highly human-dominated landscapes. The impact of roads on some aspects of ungulate behaviour has already been studied. However, potential differences in response to roads during migration, dispersal and home range movements have never been evaluated. Addressing these issues is particularly important to assess the resistance of European landscapes to the range of wildlife movement processes, and to evaluate how animals adjust to anthropogenic constraints.
\end{abstract}

Methods: We analysed 95 GPS trajectories from 6 populations of European roe deer (Capreolus capreolus) across the Alps and central Europe. We investigated how roe deer movements were affected by landscape characteristics, including roads, and we evaluated potential differences in road avoidance among resident, migratory and dispersing animals (hereafter, movement modes). First, using Net Squared Displacement and a spatio-temporal clustering algorithm, we classified individuals as residents, migrants or dispersers. We then identified the start and end dates of the migration and dispersal trajectories, and retained only the GPS locations that fell between those dates (i.e., during transience). Finally, we used the resulting trajectories to perform an integrated step selection analysis.

Results: We found that roe deer moved through more forested areas during the day and visited less forested areas at night. They also minimised elevation gains and losses along their movement trajectories. Road crossings were strongly avoided at all times of day, but when they occurred, they were more likely to occur during longer steps and in more forested areas. Road avoidance did not vary among movement modes and, during dispersal and migration, it remained high and consistent with that expressed during home range movements.

Conclusions: Roads can represent a major constraint to movement across modes and populations, potentially limiting functional connectivity at multiple ecological scales. In particular, they can affect migrating individuals that track seasonal resources, and dispersing animals searching for novel ranges.

\footnotetext{
${ }^{*}$ Correspondence: passonigioele@live.it

${ }^{1}$ Department of Zoology, University of Oxford, Zoology Research and

Administration Building, 11a Mansfield Rd, Oxford OX1 3SZ, UK

Full list of author information is available at the end of the article
}

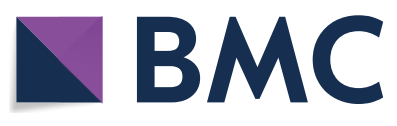

(c) The Author(s) 2021. Open Access This article is licensed under a Creative Commons Attribution 4.0 International License, which permits use, sharing, adaptation, distribution and reproduction in any medium or format, as long as you give appropriate credit to the original author(s) and the source, provide a link to the Creative Commons licence, and indicate if changes were made. The images or other third party material in this article are included in the article's Creative Commons licence, unless indicated otherwise in a credit line to the material. If material is not included in the article's Creative Commons licence and your intended use is not permitted by statutory regulation or exceeds the permitted use, you will need to obtain permission directly from the copyright holder. To view a copy of this licence, visit http://creativecommons.org/licenses/by/4.0/. The Creative Commons Public Domain Dedication waiver (http://creativeco mmons.org/publicdomain/zero/1.0/) applies to the data made available in this article, unless otherwise stated in a credit line to the data. 
Keywords: Ungulates, Roe deer, Capreolus capreolus, Migration, Dispersal, Roads, Habitat selection, Step selection analysis, Connectivity

\section{Background}

Human disturbance negatively impacts wildlife and limits animal movement globally [69]. Infrastructure, such as roads, can reduce and fragment available habitat, increase wildlife mortality due to collisions with vehicles, and act as physical barriers that can impact behaviour across a range of spatial scales [27, 29]. In recent decades, the discipline of road ecology has developed to address these issues, focusing on various animal taxa and regions $[41,68]$. In ungulates, roads can particularly hamper movement processes such as dispersal and migration (hereafter called "long range movements"), which are typically associated with long distance movements and key ecological processes [5].

Seasonal migration allows individuals to exploit spatial variation in resource availability, potentially reducing intra-specific competition and, in some cases, predation risk [35, 50]. Dispersal occurs when individuals leave their natal (or breeding) area to settle in their first (or a new) breeding range, impacting population genetic structure and metapopulation dynamics $[9,17,66]$. Long range movements ensure functional connectivity among populations, and may be particularly important for population performance in highly human dominated and mountainous areas where anthropogenic or topographic barriers may separate suitable habitat (e.g., roads, mountain ridges) [9].

In ungulates, movement and habitat selection are mainly shaped by landscape features such as topography and forest cover [19], seasonal dynamics like vegetation phenology [2], and human disturbance [56]. Some of these aspects, in particular the impact of roads on resident, migratory or dispersing animals, have already been investigated in a number of systems. For example, roads significantly reduced long-distance movements in reindeer (Rangifer tarandus) in Norway [6], and limited gene flow among different populations of roe deer in Switzerland [39]. Mule deer (Odocoileus hemionus) were also shown to avoid roads and move faster when migrating across roads [56].

Despite this body of knowledge, potential differences in response to roads during different movement modes, in particular residency, dispersal and migration as observed in partially migratory populations, have never been evaluated. Since habitat selection along these movement modes can differ [38], animals may show different responses to semi-permeable barriers such as roads. In resident individuals, roads can alter space use within the home range $[8,19]$ and increase home range size and mortality risk $[36,46]$. Indeed, mortality risk was shown to be higher for roe deer (Capreolus capreolus) moving in unfamiliar areas on the outskirts of their home range [32]. By shaping space use [52, 53], site familiarity could therefore lead to a relatively strong road avoidance in resident individuals.

Long distance movements can also be costly in humandominated environments, as they increase the likelihood of crossing roads [59]. Moving into new areas carries costs, and venturing out of an established home range can force individuals through areas with higher road densities. For example, Benoit et al. [5] showed that dispersing roe deer spent more energy than resident individuals, especially when moving through fragmented areas with high road densities. Additionally, site familiarity during long range movements can vary. Migration is a recurrent behaviour that generally occurs annually and can be culturally transmitted [37]. While migrating, animals may therefore have some familiarity with the surrounding landscape [58], and may be able to avoid roads more effectively. On the other hand, dispersal mostly occurs through unfamiliar landscapes [24]. As such, knowledge of the spatial distribution of roads and associated sources of risk is likely lower or absent. Addressing these issues is particularly important to assess the resistance of humandominated landscapes to the range of different wildlife movements, and to evaluate how animals adjust their behaviour to anthropogenic constraints.

In this study, we focused on six populations of European roe deer across the Alps and central Europe, with two main objectives: (i) to investigate how roe deer movements are affected by roads and other landscape characteristics; and (ii) to identify potential differences in road avoidance among resident, migratory and dispersing animals. The European roe deer is a widespread ungulate in Europe that lives in habitats as diverse as boreal forests and Mediterranean shrublands [42]. They are behaviourally flexible, showing a wide variety of movement modes, from sedentary behaviour to migration, as well as several tactics of natal dispersal [26]. In the populations considered in this study, the roe deer is a partial and facultative migrator, with only part of the population migrating each year, generally following the elevation gradient $[13,50]$. In turn, roe deer dispersal is a relatively conserved behaviour across populations [30].

To investigate movement-specific habitat selection and test for differences in road avoidance among 
different movement modes, we performed an integrated step selection analysis (iSSA, [4]). We expected roe deer movements to be affected by resource availability, landscape topography and risk avoidance. With regards to resources, we predicted that roe deer should select areas with higher NDVI values (Normalised Difference Vegetation Index-i.e., a proxy for the availability of food). Roe deer should also minimise unnecessary energy expenditure, and thus the altitude gains and losses along their movement trajectories. We expected roe deer to avoid risks, especially those linked to human disturbance. In this context, roe deer should select forested areas further away from roads during the day, and more open areas closer to roads during the night time $[8,40]$. Moreover, when close to roads, roe deer should select areas with higher forest density [19] in order to seek protection from human disturbance, as shown for other ungulates $[34,51]$. With regards to how road avoidance may vary among movement modes, we predicted that it should be strongest for resident individuals with relatively high site familiarity and weakest for dispersers that move longer distances across unknown landscapes, with intermediate levels for migratory individuals.

\section{Methods}

Animal relocation data and study areas

The data used for this study were obtained from the EURODEER database of the EUROMAMMALS initiative (www.euromammals.org), a collaborative science project that stores and manages spatial data of European mammals from across Europe. We initially considered data from 344 individuals fitted with GPS collars between 2004 and 2015, for a total of 2,264,497 locations. Intervals between consecutive locations spanned between $15 \mathrm{~min}$ and $12 \mathrm{~h}$.

The collared individuals were from six different populations in mountainous or sub-mountainous areas in the Alps and central Europe (Fig. 1-Switzerland: Bernese Oberland ( $\mathrm{n}=74)$; Italy: Val Rendena ( $\mathrm{n}=27$ individuals), Monte Bondone ( $\mathrm{n}=26$ individuals); Germany: Bavarian Forest ( $\mathrm{n}=179$ individuals), Hegau ( $\mathrm{n}=12$ individuals); Austria: Leoben ( $\mathrm{n}=26$ individuals)).

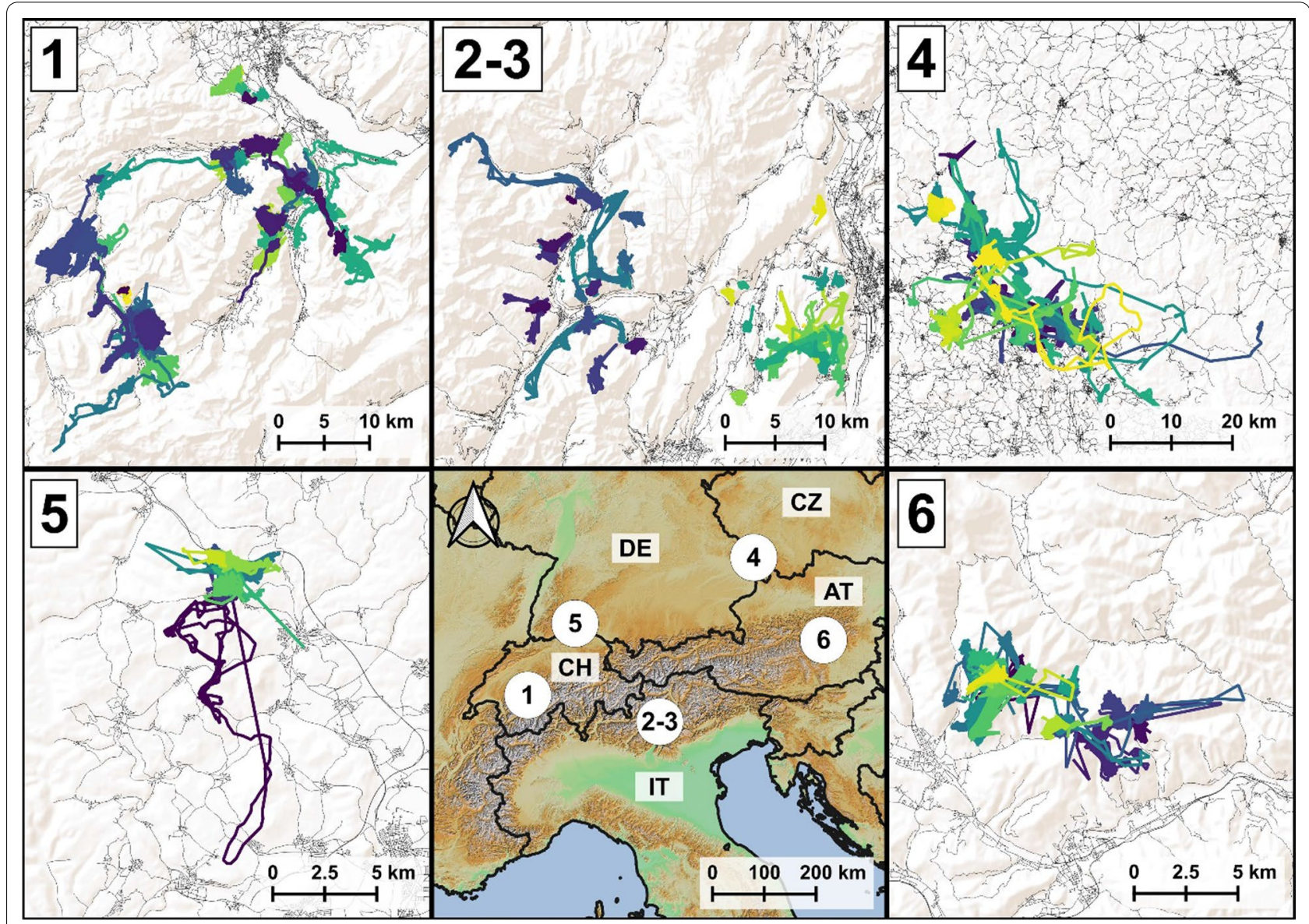

Fig. 1 Map showing the location and key information of the 6 study areas $(1=$ Bernese, $2=$ Rendena, $3=$ Bondone, $4=B a v a r i a, 5=H e g a u$, $6=$ Leoben). For each area, we show the trajectories of the GPS tracked roe deer, the road network and the digital elevation model 
Despite being different in many aspects, the selected areas are characterised by a mountainous topography, the presence of natural or semi-natural areas, and a limited proportion of agricultural areas. Roads, human settlements and urban areas are mostly concentrated at the bottom of the valleys (see Additional file 1 for more information about study areas). Furthermore, individuals in these populations are known to perform all the movement modes considered in this study (i.e., home range movements, migration, dispersal).

\section{Movement data management and classification of movement patterns}

From the initial dataset, we retained only the individuals with a fix interval of up to $5 \mathrm{~h}$. Between January and March, movements are generally limited within the winter ranges. As such, we selected the GPS trajectories with at least 10 months of data from a start date between 1 and $31^{\text {st }}$ March to an end date between the 1st and 31st January of the following year. These dates were chosen based on Peters et al. [50] and Peters et al. [49] to ensure that we captured migration and dispersal events, and to maximise sample size. Each GPS trajectory was then truncated by discarding locations falling outside of our specified date window.

In order to classify movement patterns, we used the Net Squared Displacement method (NSD-[11]). The NSD is calculated as the squared geographical distance of each GPS location from a first, reference location. In this case, we ensured that the first location fell in an animal's winter range. The NSD method fits several non-linear models to the observed NSD values, each representing a movement mode (i.e. resident, migrant, disperser). The best model, which classifies the movement pattern of each individual, is then selected based on the Akaike Information Criteria (AIC) [11]. The NSD analyses were conducted using the 'migrateR' package Spitz et al. [64] - parameters available in Additional file 1) in $R$ 3.5.1 (R Development Core Team 2013). Animal trajectories were also spatially investigated using SeqScan, a spatio-temporal clustering algorithm available in the QGIS plugin 'MigrO' which has previously proved effective for the analysis of movement patterns from GPS trajectories $[21,22]$. The use and comparison of multiple methods is recommended for a more accurate classification of movement patterns, especially in species like roe deer with a wide range of movement behaviours [12]. If the classification was ambiguous using the NSD method and SeqScan, the trajectory was discarded.

Because we were interested in comparing step selection among different movement modes, for migration and dispersal, we only retained the trajectory of the transience phase (i.e. the segment of trajectory during the period of migration and dispersal). To do this, we identified the start and end dates of these events from the NSD plot using the 'locator()' function in the 'graphics' R package and we used these dates to truncate the trajectories. As such, spring migration trajectories start from the time when an animal leaves its winter range to the time it settles in the summer range. Similarly, for dispersal trajectories, we considered only the movement between the two ranges, ignoring locations within the two ranges. Stopovers and multi-trip migrations (i.e. including multiple trips between seasonal ranges before settling-[13]) were included, as long as they occurred in the isolated segments. The trajectories of resident individuals were truncated using the median start and end times of migratory animals in order to evaluate behaviour during comparable periods. We report these values in the results section.

Once we classified each movement category and obtained the trajectories, we excluded all the individuals with a gap of more than 7 days of consecutive missing data. All trajectories were then re-sampled by retaining points at a fix interval of 3 to $5 \mathrm{~h}$. We did not re-sample to a single fix interval because trajectories can only be re-sampled to a multiple of the original fix intervals, which in our case were 3,4 and $5 \mathrm{~h}$ (i.e. the least common multiple would be $60 \mathrm{~h}$, which is much larger than the scale we wanted to focus on). Following this process, we retained a total of 95 trajectories from 79 individuals, which represent the final dataset used in the model (Italy: Val Rendena ( $\mathrm{n}=10$ individuals), Monte Bondone $(n=9)$; Germany: Bavarian Forest $(n=26)$, Hegau $(n=2)$; Switzerland: Bernese Oberland $(\mathrm{n}=31)$; Austria: Leoben $(n=1))$. The re-sampling of the trajectories was carried out using the R package 'adehabitatLT' [14].

\section{Integrated step selection analysis}

In order to assess the impact of spatial variation in resources, topography, and roads on roe deer movement, we conducted an integrated step selection analysis (iSSA-[4]). iSSA jointly estimates resource selection and animal movement parameters (e.g. step length), by relaxing the implicit assumption that these are independent [4].

In iSSA, each observed animal step (i.e., movement between two consecutive GPS fixes) is compared to a set of random steps (i.e., that animal could have taken) using conditional logistic regression. In this study, we matched each observed step with 10 random steps, computed using distances sampled from a gamma distribution fitted to the empirical step length distribution and random turning angles, using the $\mathrm{R}$ package 'amt' [62] (see Additional file 1 for the step length and turning angle distributions used to generate random steps). Because our trajectories had different fix 
intervals ranging between 3 and $5 \mathrm{~h}$, for each fix interval we generated random steps using the distribution of steps at the corresponding interval (e.g., random steps for an individual with a fix interval of $3 \mathrm{~h}$ were generated using the step distribution of individuals with a fix interval of $3 \mathrm{~h}$ ) (see Additional file 1). The number of random steps was chosen based on the recommendations of Thurfjell et al. [67], to create a sufficiently large sample size while preventing excessively long computational processing times. To ensure that 10 random steps were enough, we performed a sensitivity analysis by running separate models using 1 to 10 random steps, and recorded model coefficients for each model (see Additional file 1).
We extracted environmental covariates at the end of each step, together with the number of road crossings along each step, the time of day (categorical: day, twilight, night-see Additional file 1 for details on how this was calculated) and step length (see Table 1 for the complete list of variables). All variables were scaled and centred, and screened for collinearity using the Pearson's correlation coefficient with a threshold of $|\mathrm{r}|>0.7$ [25]. We performed an iSSA using mixed-effect conditional logistic regression to identify the main predictors of movement using the full set of covariates (see Table 2 for model terms), since we did not find any substantial collinearity between variables (see Additional file 1 for correlation matrix). To account for differences

Table 1 Variables used in the model. For each variable we report the resolution, a general description of the variable and the source from which the variable was obtained

\begin{tabular}{|c|c|c|c|}
\hline Variable & Resolution & Description & Source \\
\hline Elevation difference & $25 \mathrm{~m}$ & Difference in altitude between start and end of a step & $\begin{array}{l}\text { European Environment Agency (EEA) - EU Copernicus. } \\
\text { European Digital Elevation Model (EU-DEM), version } 1.1\end{array}$ \\
\hline Slope & $25 \mathrm{~m}$ & Slope in degrees (0-90) & $\begin{array}{l}\text { European Environment Agency (EEA) - EU Copernicus. } \\
\text { European Digital Elevation Model (EU-DEM), version } 1.1\end{array}$ \\
\hline Forest density & $20 \mathrm{~m}$ & Percentage of area covered by trees (0-100\%) & European Environment Agency, 2012 \\
\hline $\mathrm{NDVI}$ & $250 \mathrm{~m}$ & Mean NDVI value (time series of 8 days composite) & $\begin{array}{l}\text { Modis - Institute of Surveying, Remote Sensing and Land } \\
\text { Information of the University of Natural Resources and } \\
\text { Applied Life Sciences, Vienna (2004-2015) }\end{array}$ \\
\hline Road crossings & - & Number of road crossings per step & Open street map. Only paved roads were considered \\
\hline Time of day & - & $\begin{array}{l}\text { Categorical (day, twilight, night) (see Additional file } 1 \text { for } \\
\text { details on how it was calculated) }\end{array}$ & GPS collar data \\
\hline Log(Step length) & - & $\begin{array}{l}\text { Natural logarithm of hourly step length in meters (see } \\
\text { Additional file 1) }\end{array}$ & GPS collar data \\
\hline Movement mode & - & Categorical (Resident, migrant or disperser) & Analysis (see main text) \\
\hline Sex & - & Categorical (Sex of the individual) & Collected at capture \\
\hline
\end{tabular}

Table 2 Terms used in the step selection function with the associated predictions

\begin{tabular}{|c|c|}
\hline Model terms & Predictions \\
\hline Forest Density + Forest density: Time of day & Selection of more forested areas during the day and more open areas during night time [8] \\
\hline Slope + Slope $^{2}$ & $\begin{array}{l}\text { Selection of flatter areas [31]. A quadratic term was added to evaluate selection of slopes with interme- } \\
\text { diate steepness }\end{array}$ \\
\hline Elevation difference + Elevation difference ${ }^{2}$ & Selection of steps with low elevation difference - i.e. low elevation gain/loss (i.e. around zero) \\
\hline$N D V I+N D V I^{2}$ & $\begin{array}{l}\text { Selection of areas with higher NDVI values. A quadratic term was added to evaluate selection of inter- } \\
\text { mediate values, especially during migration [57] }\end{array}$ \\
\hline Road crossings & General avoidance of road crossings [51] \\
\hline Road crossings: Time of day & $\begin{array}{l}\text { Road crossings should be avoided at all times of day, but particularly during the day and twilight, when } \\
\text { traffic is more intense }[40,47]\end{array}$ \\
\hline Road crossings: Forest density & Road crossings should occur preferentially in more forested areas $[19,51]$ \\
\hline Road crossings: Movement mode & $\begin{array}{l}\text { Road avoidance should be strongest for resident individuals, intermediate for migrants and weakest for } \\
\text { dispersers }\end{array}$ \\
\hline $\log ($ Step length) & Statistical estimator of the parameters of the assumed step-length distribution [4] \\
\hline $\log ($ Step length): Sex & Control to account for potentially different step lengths between sexes \\
\hline Road crossings: log(Step length) & Control to account for the fact that longer steps are more likely to cross roads \\
\hline Road crossings: Sex & Control to account for potentially different road avoidance between sexes \\
\hline
\end{tabular}


in habitat selection during different times of the day and when crossing roads [51], we added interactions between forest density and time of day, number of road crossings and time of day, and forest density and number of road crossings. To specifically test for differences in road avoidance among the three movement modes, we added the interaction between number of road crossings and the movement mode of each individual. To control for the fact that longer steps are statistically more likely to cross roads, we included an interaction between number of road crossings and the natural logarithm of step length [4]. To account for the fact that our trajectories had different fix intervals and to avoid biased model coefficients, we used the hourly step length, obtained by dividing each step length by the relative fix interval (Table 1, Additional file 1; see Additional file 1 also for model coefficients at different fix intervals). Finally, we controlled for potential differences in step length and number of road crossings for the two sexes. Nested random effects were included for individuals and populations to control for repeated measures. This decision was made to account for unequal number of steps for each individual and unequal numbers of individuals in each population. Models were fitted using the R package 'coxme' $[65,70]$. We also attempted to account for variation among individuals by fitting random slopes using multiple approaches described by Muff et al. [45], Craiu et al. [20], and Therneau [65] unfortunately failing due to convergence issues (see Additional file 1 for the $\mathrm{R}$ code with the attempts to run these models and the section "Caveats and Potential Biases" in the Discussion).

The importance of each explanatory variable in predicting habitat selection was assessed by removing one variable at a time from the full model, which included all predictors, and recording the change in AIC value for each sub-model (here called $\triangle \mathrm{AIC}_{\mathrm{REMOVED}}$ ). The most important variables were identified as those that, when removed, caused the highest increase in AIC (i.e. the variables with the highest $\left.\triangle \mathrm{AIC}_{\mathrm{REMOVED}}\right)$.

\section{Results}

\section{Trajectories and movement patterns}

Of the 95 retained trajectories, 25 were migratory events, 8 were dispersal events and 62 were extracted from resident individuals.

The median start date for migration was 6 April (min. 29 February; max. 3 May), while the median end date was 23 May (min. 25 March; max. 10 September). For dispersal, the median start date was 4 May (min. 28 February; max. 2 August) and the median end date was 7 June (min. 17 March; max. 20 August). For all resident animals, the start and end dates were set to 10 April and 27 May (i.e. the median start and end date for migration and dispersal), respectively. The median durations for migration, dispersal and resident movements were 61 days (min. 20; max. 192), 27 days (min. 16; max. 65) and 47 days (min. 47; max. 47; by definition), respectively.

\section{Integrated step selection analysis}

In Table 3, we report the coefficients and confidence intervals of the full model, as well as the $\triangle \mathrm{AIC}_{\mathrm{REMOVED}}$ for each variable. The most important variables were forest density $\left(\triangle \mathrm{AIC} C_{\mathrm{REMOVED}}=1784\right)$, its interaction with time of day $\left(\triangle \mathrm{AIC} \mathrm{REMOVED}_{\mathrm{R}}=1738\right)$, and number of road crossings $\left(\triangle A I C_{\text {REMOVED }}=1076\right)$. Despite most of the other variables being significant, they were relatively less important for explaining step selection (Table 3).

In general, roe deer tended to select steps with higher forest density during the day, but with more open habitat during night time (day: $\beta=0.35 ; 95 \%$ CI [0.32, 0.37], night compared to day: $\beta=-0.79 ; 95 \%$ CI $[-0.83$, $-0.75]-$ Table 2, Fig. 2). Roads were strongly avoided at all times of the day ( $\beta=-1.38 ; 95 \%$ CI $[-1.51,-1.25])$, but were crossed more frequently in areas with higher forest density $(\beta=0.07 ; 95 \%$ CI $[0.05,0.09])$. The number of road crossings increased with step length $(\beta=0.23$; $95 \%$ CI $[0.21,0.26])$. Furthermore, males tended to have longer steps than females (females: $\beta=-0.407 ; 95 \%$ CI $[-0.43,-0.39]$; males vs females: $\beta=0.143$; $95 \% \mathrm{CI}$ $[0.119,0.168])$.

On average, roe deer tended to select areas with slopes of intermediate steepness, at around $10^{\circ}(\beta=-0.08$; 95\% CI $[-0.09,0.06])$, and minimised altitude gains or losses along their steps, as shown by the negative coefficient for the squared elevation difference term $(\beta=-0.01 ; 95 \% \mathrm{CI}$ $[-0.02,-0.01])$. NDVI was the penultimate variable in the model in terms of importance $\left(\triangle \mathrm{AIC} C_{\mathrm{REMOVED}}=24\right)$, despite having a positive and significant coefficient $(\beta=0.06 ; 95 \%$ CI $[0.01,0.11])$. The interaction between movement mode and number of road crossings was not significant (dispersers compared to residents: $\beta=0.01$; 95\% CI [-0.06, 0.08], migrants compared to residents: $\beta=0.03 ; 95 \% \mathrm{CI}[-0.02,0.08])$ and was the least important variable in our model $\left(\triangle \mathrm{AIC} \mathrm{REMOVED}_{\mathrm{R}}=7\right)$.

\section{Discussion}

Using an integrated step selection approach, we investigated habitat selection of roe deer during various movement modes across six populations in mountainous regions with a significant human footprint. We showed that roe deer mainly selected forested areas, minimised elevation differences along their movement trajectories, and consistently minimised the number of roads crossed during migration, dispersal, and home range movements.

As expected, we found that higher forest densities were selected during the day, while less forested areas 
Table 3 Summary of the full model showing model coefficients $(\beta)$ with 95\% confidence intervals, the standard deviation of the random effects, and the number of observations

\begin{tabular}{|c|c|c|c|c|}
\hline Variable & Categories & $\beta$ & 95\% C.I. & $\Delta \mathrm{AIC}_{\text {REMOVED }}$ \\
\hline log(Step length) & - & -0.407 & {$[-0.425,-0.389]$} & 4697 \\
\hline Forest density & - & 0.347 & {$[0.324,0.371]$} & 1784 \\
\hline \multirow[t]{3}{*}{ Forest density: Time of day } & Day (Ref.) & 0.347 & {$[0.324,0.371]$} & 1738 \\
\hline & Night & -0.787 & {$[-0.825,-0.749]$} & \\
\hline & Twilight & -0.423 & {$[-0.486,-0.36]$} & \\
\hline Road crossings & - & -1.379 & {$[-1.505,-1.252]$} & 1076 \\
\hline Road crossings : log(Step length) & - & 0.231 & {$[0.205,0.257]$} & 284 \\
\hline \multirow[t]{2}{*}{$\log ($ Step length) : Sex } & Female (Ref.) & -0.407 & {$[-0.425,-0.389]$} & 142 \\
\hline & Male & 0.143 & {$[0.119,0.168]$} & \\
\hline Slope & - & 0.107 & {$[0.081,0.133]$} & 129 \\
\hline Slope ${ }^{2}$ & - & -0.076 & {$[-0.092,-0.06]$} & 98 \\
\hline Road crossings : Forest density & - & 0.068 & {$[0.046,0.09]$} & 44 \\
\hline \multirow[t]{3}{*}{ Road crossings : Time of day } & Day (Ref.) & -1.379 & {$[-1.505,-1.252]$} & 29 \\
\hline & Night & 0.110 & {$[0.065,0.156]$} & \\
\hline & Twilight & 0.047 & {$[-0.034,0.129]$} & \\
\hline Elevation difference $^{2}$ & - & -0.014 & {$[-0.02,-0.007]$} & 28 \\
\hline Elevation difference & - & 0.003 & {$[-0.015,0.021]$} & 26 \\
\hline $\mathrm{NDVI}$ & - & 0.056 & {$[0.005,0.107]$} & 24 \\
\hline \multirow[t]{2}{*}{ Road crossings : Sex } & Female (Ref.) & -1.379 & {$[-1.505,-1.252]$} & 16 \\
\hline & Male & -0.066 & {$[-0.111,-0.02]$} & \\
\hline $\mathrm{NDVl}^{2}$ & - & -0.023 & {$[-0.047,0.002]$} & 11 \\
\hline \multirow{3}{*}{$\begin{array}{l}\text { Road crossings : Movement } \\
\text { mode }\end{array}$} & Resident (Ref.) & -1.379 & {$[-1.505,-1.252]$} & 7 \\
\hline & Disperser & 0.010 & {$[-0.061,0.081]$} & \\
\hline & Migrant & 0.030 & {$[-0.023,0.084]$} & \\
\hline Random effects & \multicolumn{2}{|c|}{ Standard deviation } & & \\
\hline Individual animals $(\mathrm{N}=79)$ & 0.041 & & & \\
\hline Populations $(\mathrm{N}=6)$ & 0.020 & & & \\
\hline \multicolumn{4}{|c|}{ Number of events: 26892 observed +268920 random steps } & \\
\hline
\end{tabular}

"Ref." indicates the category of reference for categorical variables. For each variable, we also report the $\triangle \mathrm{AIC} \mathrm{REMOVED}_{\mathrm{i}}$, i.e., the difference in AIC between the full model and the full model without that variable. Hence, the variables with the highest $\triangle A I C_{\text {REMOVED }}$ are the most important because, when removed, they caused the highest increase in AIC. Variables are listed in order of importance. The AIC of the full model including all variables was $129,748$.

were visited more frequently at night, in accordance with other studies investigating roe deer habitat selection $[8,23]$. Roads were strongly avoided at all times of the day, and crossings tended to be more common during longer movements. Roads have been shown to limit movement and space use in many animal taxa, including large carnivores [18], small mammals [33], reptiles [61], amphibians [15], and even fish [48]. In ungulates, road crossings were avoided also by elk (Cervus canadensis), pronghorn (Antilocapra americana) and moose in North America [7, 51, 60], and reindeer in Norway [6]. Studies on roe deer had previously suggested that they avoid roads at the home range scale, although focusing on the distance to the nearest road [19], rather than actual crossings. We found that when animals did cross roads, they also tended to end their steps in more forested areas, potentially to seek protection and reduce risk of exposure to predators and disturbance, as shown for elk in North America [51]. Coulon et al. [19] and Bonnot et al. [8] also showed that roe deer selected forested areas more strongly when in proximity of roads.

In general, roe deer selected slopes of intermediate steepness $\left(\sim 10^{\circ}\right)$ as also found by Ranc et al. [52]. However, this differed from other studies arguing that roe deer should select flatter areas to minimise energy expenditure [31]. Our result may be due to the fact that, in human-dominated mountainous areas like those considered here, urbanisation and human activities are usually concentrated in the lower and flatter parts of the valley. Nonetheless, minimisation of energy expenditure is likely the reason why we found that roe deer also 

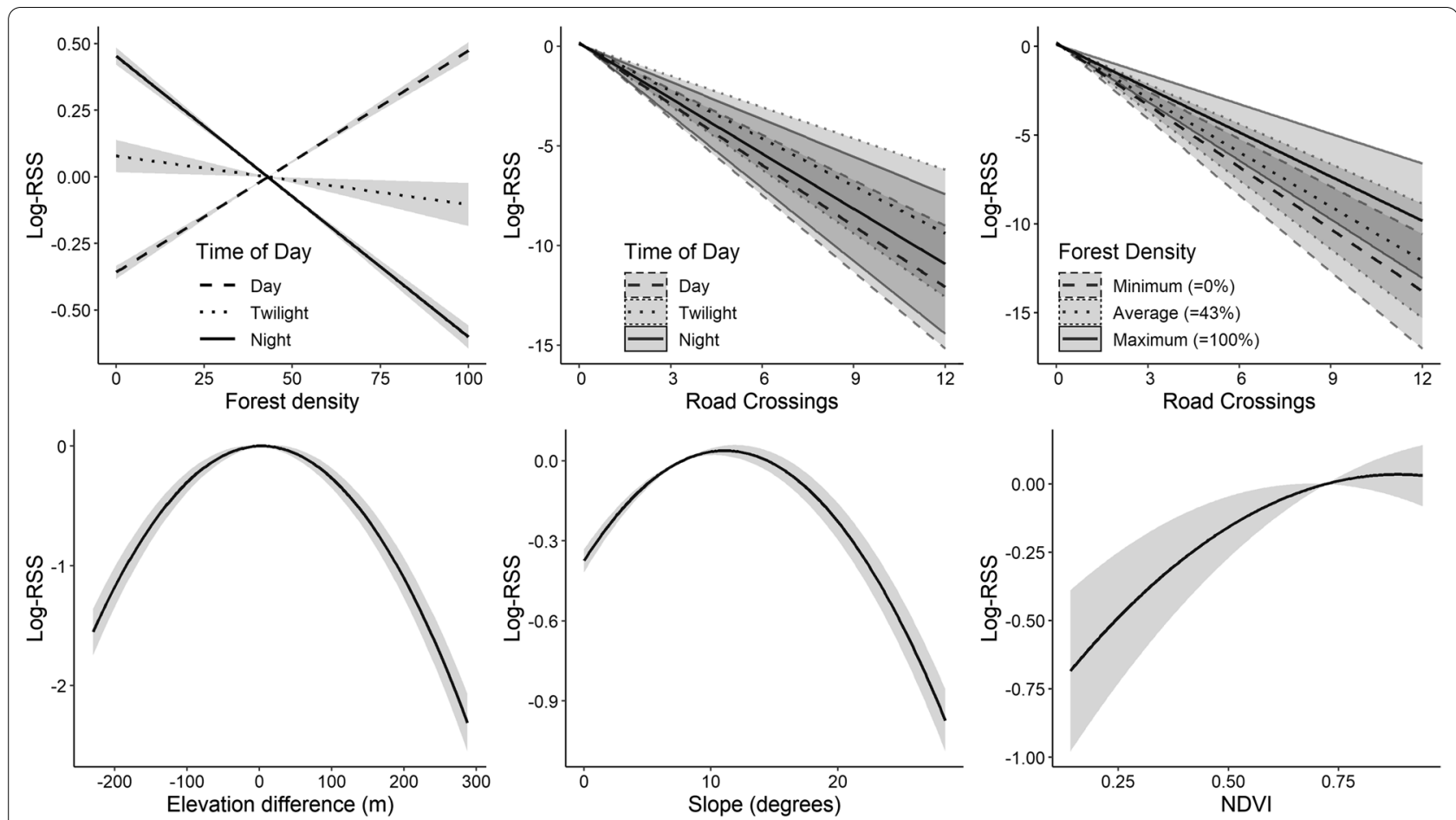

Fig. 2 Response curves calculated using the fixed effect coefficients of the step selection function and showing the Relative Selection Strength (Log-RSS) for the most important model predictors with 95\% confidence intervals (shaded areas) [3]. The range of values of the predictors on the $x$-axis corresponds to observed ranges, thus meaning that we did not project the predictions to unobserved or unrealistic values

tended to minimise elevation gained or lost along their movements. Moreover, in summer, mountain ungulates tend to follow the elevation green up of the vegetation ('surfing the green wave', e.g. Aikens et al. [1]. Hence, excessively large altitudinal displacements may result in a spatial mismatch between the location of the animal and the distribution of optimal resources [1]. In the French Alps, larger displacements towards high elevations were observed in correspondence of higher primary productivity, where more abundant resources could compensate for higher movement costs [31]. In our case, NDVI had only a weak positive effect on roe deer step selection. This may be due to the fact that, in human-dominated landscapes, the effects of anthropogenic disturbance on ungulate behaviour can exceed those of natural processes [16]. It is therefore possible that roe deer are forced to select sub-optimal resources in order to avoid roads and other sources of human disturbance [16]. Nonetheless, it is also possible that the resolution of the NDVI variable considered in this study (8-day average at $250 \mathrm{~m}$ ) may be too coarse to capture its effect on roe deer step selection (average step length $\approx 159 \mathrm{~m}$ in $3 \mathrm{~h}$ ). In accordance with this, Aikens et al. [2] showed that roe deer do not follow the plant green up as closely as other species, but select the most productive habitats at a finer scale [43].
We did not find any evidence that road avoidance varied across migration, dispersal or home range movements. In other words, although roe deer may be less familiar with the landscape, and may be forced to frequently cross roads during migration and dispersal [5], their level of road avoidance remained high and consistent with that expressed during home range movements. Roads can therefore pose a significant barrier for migrating roe deer to reach seasonal ranges and potentially access better resources [50,63], and for dispersing roe deer to establish in a novel range, thus connecting spatially distinct populations [26]. In a partially migratory species, this may thus constrain migratory movements and reduce the relative proportion of migrants in highroad density areas. However, road crossings inevitably still occur, and resulting collisions with vehicles represent an important cause of mortality for roe deer in Europe, especially in relation to migration and dispersal events [55]. Additionally, even with regards to resident movements, the high level of road avoidance suggests a general constraint of human infrastructure on roe deer mobility. Future studies should focus on investigating fine scale behavioural adjustments to such constraints. For example, roads, as a source of risk, might be kept at the periphery of the home range (Seigle-Ferrand et al. 
unpubl.). This hypothesis is supported by recent work on the role of familiarity in shaping resource use [52,54] and risk avoidance, whereby roe deer are more likely to constrain their movements to familiar areas, even within an established home range, where they experience lower mortality [32].

Further research is also needed to evaluate the impact and consequences of human disturbance for dispersal and metapopulation functioning. We showed that road avoidance behaviour did not vary between resident $(\mathrm{n}=62)$ and migratory $(\mathrm{n}=25)$ individuals. However, due to low data availability, we could not draw strong conclusions for dispersing individuals $(\mathrm{n}=8)$. Another priority for research is to integrate other behavioural processes among the drivers of movement. For example, it has been shown that memory plays an important role in ungulate movement and space use [10]. However, most studies integrating memory in habitat selection analysis have focused on space use within the home range, with a few exceptions [10, 44, 52]. Finally, future research should focus on relating movement and habitat selection to energetics and demography to quantify their costs and benefits for individual performance and ultimately population dynamics.

\section{Caveats and potential biases}

In our model, we included random intercepts for individuals and populations to account for repeated measures. In order to obtain more accurate estimates and account for variation among individuals [45], we also attempted to include random slopes using multiple recently-developed methods, unfortunately without success. First, we tried using 'coxme()' [65] and the approaches proposed by Muff et al. [45]. These approaches worked well for simpler formulations of our model, providing very similar outputs as obtained without random slopes, however they failed to provide outputs as soon as the model became more complex (e.g., inclusion of interactions and nested random slopes) due to convergence issues. Indeed, these models can be challenging to fit $[28,45]$. We also tried to use the two-step approach described in Craiu et al. [20], but this was not applicable as the values of several variables in our model remained constant within all strata of at least one cluster. This is the main limitation of the two-step approach $[20,28,45]$. The $\mathrm{R}$ code used to run all the above-mentioned models is provided in Additional file 1.

Including mixed effects in conditional logistic regressions remains challenging and is a developing topic in iSSA [28]. The use of random slopes has been recommended to fully account for inter-individual heterogeneity [45]. Indeed, random-intercept-only models like the one presented here cannot account for among-individual variation in the regression slopes. Nonetheless, while we think that individual variation is important, the main aim of this study was to investigate how roads and other environmental factors can affect roe deer movement at the population level. According to recent findings, adding random slopes to our model could have produced more accurate estimates and allowed for more variance around random intercepts [45]. However, iSSAs including random slopes have also been shown to produce biased parameters when movement characteristics were included in the model (e.g. step length) $[28,45]$.

In conclusion, we are aware that including random slopes would have better accounted for uncertainty around our coefficients and possibly resulted in different estimates of effect sizes [28]. However, given the computational challenges and the scarcity of research on mixedeffect iSSAs, we could not implement any of the currently available approaches in practice. Finally, considering the coherence of our results with the vast literature on roe deer ecology, and the consistency of outputs between the different approaches when using simpler model formulations with and without random slopes, it is unlikely that adding random slopes to the full model would have significantly changed our key findings.

\section{Conclusions}

This study showed that roads can represent a major constraint to movement across populations and movement modes, even for a species with relatively low movement propensity, and can therefore limit ecological connectivity at different scales [39]. This is particularly relevant in mountainous areas, where roads are generally concentrated along valley bottoms, and high mountains can also represent barriers to individual movement and population spatial distribution. In the future, a spatially explicit model integrating other wide-ranging Alpine species (e.g. red deer, chamois, lynx, bear and wolf), could help predict the areas where roads have the strongest impact on functional connectivity, thus providing important guidance for targeted policy decisions and management interventions at the landscape scale.

\section{Abbreviations}

NSD: Net squared displacement; iSSA: Integrated step selection analysis; NDVI: Normalised difference vegetation index; AIC: Akaike Information Criteria.

\section{Supplementary Information}

The online version contains supplementary material available at https://doi. org/10.1186/s40462-021-00292-4.

Additional file 1. Chapter 1: Study area summary statistics. Chapter 2: MigrateR parameters. Chapter 3: Generation of random steps and use of 
step length as a variable in the model. Chapter 4: Sensitivity analysis for number of available steps. Chapter 5: Definition of the variable "Time of day". Chapter 6: Collinearity of model predictors. Chapter 7: Model coefficients for steps at 3- and 5-hour fix intervals. Chapter 8: R code used to fit random slopes models.

\section{Acknowledgements}

We would like to thank the EURODEER data curators for managing the data and the wider EURODEER and EUROMAMMAL communities for the fruitful discussions about this article. We are also grateful to all the people who contributed to data collection throughout the years.

\section{Authors' contributions}

GP, FC and TC conceived and designed the analysis; BG, MH, FB, RS, FC provided the data; GP performed the analysis with the support of FC, TC, NR, $A C$ and $S C ; G P$ wrote the article with major contributions from $F C, T C, A J M H$, $\mathrm{SC}$ and $\mathrm{BG}$. AM, MH and NB participated in initial discussions and revised the article. All authors read and approved the final manuscript.

\section{Funding}

Gioele Passoni is funded by the UK's Natural Environment Research Council through the Environmental Research Doctoral Training Partnership at the University of Oxford (NE/L002612/1). Andrea Corradini is funded by a PhD grant from the University of Trento (Department of Civil, Environmental and Mechanical Engineering), Fondazione Edmund Mach (Research and Innovation Centre), and Stelvio National Park. Funding in Switzerland was provided by the Federal Office for the Environment. Funding in Germany for the Bavarian Forest study area was provided by the German Federal Ministry of Transport and Digital Infrastructure through the program "Modernitätsfonds/ mFUND" project "Dynamic wildlife-vehicle-collision warning using heterogeneous traffic, accident and environmental data as well as big data approaches" (nr. 100319244); the Hegau study area was funded by the Ministry for Rural Areas and Consumer Protection Baden-Württemberg (Landesjagdabgabe Baden-Württemberg).

\section{Availability of data and materials}

All raw data used in this article are stored in the EURODEER spatial database hosted by the Fondazione Edmund Mach (https://euromammals.org) and can be accessed upon login.

\section{Declarations}

\section{Ethics approval and consent to participate}

Not applicable.

\section{Consent for publication}

Not applicable.

\section{Competing interests}

The authors declare that they have no competing interests.

\section{Author details}

${ }^{1}$ Department of Zoology, University of Oxford, Zoology Research and Administration Building, 11 a Mansfield Rd, Oxford OX1 3SZ, UK. ${ }^{2}$ Department of Biodiversity and Molecular Ecology, Research and Innovation Centre (CRI), Fondazione Edmund Mach, Via Edmund Mach 1, 38010 San Michele all'Adige, TN, Italy. ${ }^{3}$ Center for Integrated Spatial Research, Environmental Studies Department, University of California, Santa Cruz 95064, USA. ${ }^{4}$ Department of Civil, Environmental and Mechanical Engineering (DICAM), University of Trento, via Mesiano 77, 38123 Trento, TN, Italy. ${ }^{5}$ Stelvio National Park, Via De Simoni 42, 23032 Bormio, SO, Italy. ${ }^{6}$ INRAE, CEFS, Université de Toulouse, 31326 Castanet-Tolosan, France. ${ }^{7}$ LTSER ZA Pyrénées Garonne, 31320 Auzeville Tolosane, France. ${ }^{8}$ Laboratory of Wildlife Ecology and Behaviour, University College Dublin, Belfield D4, Ireland. ${ }^{9}$ Department of Evolutionary Biology and Environmental Studies, University of Zurich, Winterthurerstrasse 190, 8057 Zurich, Switzerland. ${ }^{10}$ Department of Visitor Management and National Park Monitoring, Bavarian Forest National Park, Freyunger Straße 2, 94481 Grafenau, Germany. ${ }^{11}$ Faculty of Environment and Natural Resources,
Chair of Wildlife Ecology and Management, University of Freiburg, Tennenbacher Straße 4, 79106 Freiburg, Germany. ${ }^{12}$ Institute for Forest and Wild life Management, Inland Norway University of Applied Science, 2480 Koppang, Norway. ${ }^{13}$ Wildlife Institute, Forest Research Institute Baden-Wuerttemberg, Wonnhaldestraße 4, 79100 Freiburg, Germany. ${ }^{14}$ Department of Integrative Biology and Biodiversity Research, Institute of Wildlife Biology and Game Management, University of Natural Resources and Life Sciences Vienna, Gregor-Mendel Straße 33, 1180 Vienna, Austria. ${ }^{15}$ Centre for Ecological and Evolutionary Synthesis (CEES), Department of Biosciences, University of Oslo, Blindern, P.O. Box 1066, 0316 Oslo, Norway. ${ }^{16}$ Wildlife Sciences, Faculty of Forest Sciences and Forest Ecology, University of Goettingen, Buesgenweg 3, 37077 Goettingen, Germany.

Received: 19 March 2021 Accepted: 23 October 2021

Published online: 13 November 2021

\section{References}

1. Aikens EO, Kauffman MJ, Merkle JA, Dwinnell SPH, Fralick GL, Monteith $\mathrm{KL}$. The greenscape shapes surfing of resource waves in a large migratory herbivore. Ecol Lett. 2017;20:741-50.

2. Aikens EO, Mysterud A, Merkle JA, Cagnacci F, Rivrud IM, Hebblewhite M, Hurley MA, Peters W, Bergen S, de Groeve J, Dwinnell SPH, Gehr B, Heurich M, Hewison AJM, Jarnemo A, Kjellander P, Kroschel M, Licoppe A, Linnell JDC, Merrill EH, Middleton AD, Morellet N, Neufeld L, Ortega AC, Parker KL, Pedrotti L, Proffitt KM, Said S, Sawyer H, Scurlock BM, Signer J, Stent P, Sustr P, Szkorupa T, Monteith KL, Kauffman MJ. Wave-like patterns of plant phenology determine ungulate movement tactics. Curr Biol. 2020;30:3444-3449e4.

3. Avgar T, Lele SR, Keim JL, Boyce MS. Relative selection strength: quantifying effect size in habitat- and step-selection inference. Ecol Evol. 2017;7:5322-30.

4. Avgar T, Potts JR, Lewis MA, Boyce MS, Börger L. Integrated step selection analysis: bridging the gap between resource selection and animal movement. Methods Ecol Evol. 2016;7:619-30.

5. Benoit L, Hewison AJM, Coulon A, Debeffe L, Gremillet D, Ducros D, Cargnelutti B, Chaval Y, Morellet N. Accelerating across the landscape: the energetic costs of natal dispersal in a large herbivore. J Anim Ecol. 2020;89:173-85.

6. Beyer HL, Gurarie E, Borger L, Panzacchi M, Basille M, Herfindal I, van Moorter B, LeleMatthiopoulos SRJ. "You shall not pass!": quantifying barrier permeability and proximity avoidance by animals. J Anim Ecol. 2016;85:43-53.

7. Beyer HL, Ung R, Murray DL, Fortin M-J, Frair J. Functional responses, seasonal variation and thresholds in behavioural responses of moose to road density. J Appl Ecol. 2013;50:286-94.

8. Bonnot N, Morellet N, Verheyden H, Cargnelutti B, Lourtet B, Klein F, Hewison AJM. Habitat use under predation risk: hunting, roads and human dwellings influence the spatial behaviour of roe deer. Eur J Wildl Res. 2013;59:185-93.

9. Bowler DE, Benton TG. Causes and consequences of animal dispersal strategies: relating individual behaviour to spatial dynamics. Biol Rev. 2005;80:205-25.

10. Bracis C, Mueller T. Memory, not just perception, plays an important role in terrestrial mammalian migration. Proc Biol Sci. 2017;284:20170449.

11. Bunnefeld N, Borger L, van Moorter B, Rolandsen CM, Dettki H, Solberg EJ, Ericsson G. A model-driven approach to quantify migration patterns: individual, regional and yearly differences. J Anim Ecol. 2011;80:466-76.

12. Cagnacci F, Focardi S, Ghisla A, van Moorter B, Merrill EH, Gurarie E, Heurich M, Mysterud A, Linnell J, Panzacchi M, May R, Nygard T, Rolandsen C, Hebblewhite M. How many routes lead to migration? Comparison of methods to assess and characterize migratory movements. J Anim Ecol. 2016;85:54-68.

13. Cagnacci F, Focardi S, Heurich M, Stache A, Hewison AJM, Morellet N, Kjellander P, Linnell JDC, Mysterud A, Neteler M, Delucchi L, Ossi F, Urbano F. Partial migration in roe deer: migratory and resident tactics are end points of a behavioural gradient determined by ecological factors. Oikos. 2011;120:1790-802.

14. Calenge $C$. Analysis of animal movements in $R$ : the adehabitatLT package. 2016. 
15. Cayuela H, Bonnaire E, Astruc G, Besnard A. Transport infrastructure severely impacts amphibian dispersal regardless of life stage. Sci Rep. 2019;9:8214.

16. Ciuti S, Northrup JM, Muhly TB, Simi S, Musiani M, Pitt JA, Boyce MS. Effects of humans on behaviour of wildlife exceed those of natural predators in a landscape of fear. PLOS ONE. 2012;7:e50611.

17. Clobert J, Baguette M, Benton TG, Bullock JM. Dispersal ecology and evolution. Oxford University Press; 2012.

18. Corradini A, Randles M, Pedrotti L, van Loon E, Passoni G, Oberosler V, Rovero F, Tattoni C, Ciolli M, Cagnacci F. Effects of cumulated outdoor activity on wildlife habitat use. Biol Conserv. 2021;253:108818.

19. Coulon A, Morellet N, Goulard M, Cargnelutti B, Angibault J-M, Hewison AJM. Inferring the effects of landscape structure on roe deer (Capreolus capreolus) movements using a step selection function. Landsc Ecol. 2008;23:603-14.

20. Craiu RV, Duchesne T, Fortin D, Baillargeon S. Conditional logistic regression with longitudinal follow-up and individual-level random coefficients: a stable and efficient two-step estimation method. J Comput Graph Stat. 2011;20:767-84.

21. Damiani ML, Issa H, Fotino G, Hachem F, Ranc N, Cagnacci F (2015) MigrO: a plug-in for the analysis of individual mobility behavior based on the stay region model. In: Proceedings of the 23rd SIGSPATIAL international conference on advances in Geographic Information Systems-GIS '15.

22. Damiani ML, Issa H, Fotino G, Heurich M, Cagnacci F. Introducing 'presence' and 'stationarity index' to study partial migration patterns: an application of a spatio-temporal clustering technique. Int J Geogr Inf Sci. 2015:30:907-28

23. de Groeve J, van de Weghe N, Ranc N, Neutens T, Ometto L, Rota-Stabelli O, Cagnacci F, Dray S. Extracting spatio-temporal patterns in animal trajectories: an ecological application of sequence analysis methods. Methods Ecol Evol. 2016;7:369-79.

24. Debeffe L, Morellet N, Cargnelutti B, Lourtet B, Coulon A, Gaillard JM, Bon R, Hewison AJM. Exploration as a key component of natal dispersal: dispersers explore more than philopatric individuals in roe deer. Anim Behav. 2013;86:143-51.

25. Dormann CF, Elith J, Bacher S, Buchmann C, Carl G, Carré G, Marquéz JRG, Gruber B, Lafourcade B, Leitão PJ, Münkemüller T, McClean C, Osborne PE, Reineking B, Schröder B, Skidmore AK, Zurell D, Lautenbach S. Collinearity: a review of methods to deal with it and a simulation study evaluating their performance. Ecography. 2013;36:27-46.

26. Ducros D, Morellet N, Patin R, Atmeh K, Debeffe L, Cargnelutti B, Chaval Y, Lourtet B, Coulon A, Hewison AJM. Beyond dispersal versus philopatry? Alternative behavioural tactics of juvenile roe deer in a heterogeneous landscape. Oikos. 2020;129:81-92.

27. Fahrig L, Rytwinski T. Effects of roads on animal abundance: an empirical review and synthesis. Ecol Soc. 2009;14:21.

28. Fieberg J, Signer J, Smith B, Avgar T. A "How to" guide for interpreting parameters in habitat-selection analyses. J Anim Ecol. 2021;90:1027-43.

29. Forman RT, Sperling D, Bissonette JA, Clevenger AP, Cutshall CD, Dale VH, Fahrig L, France RL, Goldman CR, Heanue K. Road ecology: science and solutions. Washington: Island Press; 2003.

30. Gaillard JM, Hewison AJ, Kjellander P, Pettorelli N, Bonenfant C, van Moorter B, Liberg O, Andren H, van Laere G, Klein F, Angibault JM, Coulon A, Vanpe C. Population density and sex do not influence fine-scale natal dispersal in roe deer. Proc Biol Sci. 2008;275:2025-30.

31. Gaudry W, Said S, Gaillard JM, Chevrier T, Loison A, Maillard D, Bonenfant C. Partial migration or just habitat selection? Seasonal movements of roe deer in an Alpine population. J Mammal. 2015;96:502-10.

32. Gehr B, Bonnot NC, Heurich M, Cagnacci F, Ciuti S, Hewison AJM, Gaillard JM, Ranc N, Premier J, Vogt K, Hofer E, Ryser A, Vimercati E, Keller L. Stay home, stay safe-Site familiarity reduces predation risk in a large herbivore in two contrasting study sites. J Anim Ecol. 2020;89:1329-39.

33. Grilo C, Molina-Vacas G, Fernández-Aguilar X, Rodriguez-Ruiz J, Ramiro V, Porto-Peter F, Ascensão F, Román J, Revilla E. Species-specific movement traits and specialization determine the spatial responses of small mammals towards roads. Landsc Urban Plan. 2018;169:199-207.

34. Hebblewhite M, Merrill E. Trade-offs between predation risk and forage differbetween migrant strategies in a migratory ungulate. Ecology. 2009;90:3445-54

35. Hebblewhite M, Merrill EH. Multiscale wolf predation risk for elk: does migration reduce risk? Oecologia. 2007;152:377-87.
36. Jerina K. Roads and supplemental feeding affect home-range size of Slovenian red deer more than natural factors. J Mammal. 2012;93:1139-48.

37. Jesmer BR, Merkle JA, Goheen JR, Aikens EO, Beck JL, Courtemanch AB, Hurley MA, McWhirter DE, Miyasaki HM, Monteith KL, Kauffman M. Is ungulate migration culturally transmitted? Evidence of social learning from translocated animals. Science. 2018;361:1023-5.

38. Killeen J, Thurfiell H, Ciuti S, Paton DG, Musiani M, Boyce MS. Habitat selection during ungulate dispersal and exploratory movement at broad and fine scale with implications for conservation management. Mov Ecol. 2014;2:1-13.

39. Kuehn R, Hindenlang KE, Holzgang O, Senn J, Stoeckle B, Sperisen C. Genetic effect of transportation infrastructure on roe deer populations (Capreolus capreolus). J Hered. 2007;98:13-22.

40. Lagos $L$, Picos J, Valero E. Temporal pattern of wild ungulate-related traffic accidents in northwest Spain. Eur J Wildl Res. 2012;58:661-8.

41. Laurance WF, Goosem M, Laurance SG. Impacts of roads and linear clearings on tropical forests. Trends Ecol Evol. 2009;24:659-69.

42. Linnell JDC. The European roe deer: a portrait of a successful species. The European roe deer: the biology of success. Oslo: Scandinavian University Press; 1998.

43. Mancinelli S, Peters W, Boitani L, Hebblewhite M, Cagnacci F. Roe deer summer habitat selection at multiple spatio-temporal scales in an Alpine environment. Hystrix Ital J Mammal. 2015. https://doi.org/10.4404/hystr ix-26.2-11223.

44. Merkle JA, Sawyer H, Monteith KL, Dwinnell SPH, Fralick GL, Kauffman MJ. Spatial memory shapes migration and its benefits: evidence from a large herbivore. Ecol Lett. 2019;22:1797-805.

45. Muff S, Signer J, Fieberg J. Accounting for individual-specific variation in habitat-selection studies: efficient estimation of mixed-effects models using Bayesian or frequentist computation. J Anim Ecol. 2020;89:80-92.

46. Niemi M, Matala J, Melin M, Eronen V, Järvenpää H. Traffic mortality of four ungulate species in southern Finland. Nat Conserv. 2015;11:13-28.

47. Paton DG, Ciuti S, Quinn M, Boyce MS. Hunting exacerbates the response to human disturbance in largeherbivores while migrating through a road network. Ecosphere. 2017. https://doi.org/10.1002/ecs2.1841.

48. Pépino M, Rodríguez MA, Magnan P. Impacts of highway crossings on density of brook charr in streams. J Appl Ecol. 2012;49:395-403.

49. Peters W, Hebblewhite M, Mysterud A, Eacker D, Hewison AJM, Linnell JDC, Focardi S, Urbano F, de Groeve J, Gehr B, Heurich M, Jarnemo A, Kjellander P, Kröschel M, Morellet N, Pedrotti L, Reinecke H, Sandfort R, Sönnichsen L, Sunde P, Cagnacci F. Large herbivore migration plasticity along environmental gradients in Europe: life-history traits modulate forage effects. Oikos. 2019;128:416-29.

50. Peters W, Hebblewhite M, Mysterud A, Spitz D, Focardi S, Urbano F, Morellet N, Heurich M, Kjellander P, Linnel J, Cagnacci F. Migration in geographic and ecological space by a large herbivore. Ecol Monogr. 2017:87:297-320.

51. Prokopenko CM, Boyce MS, Avgar T, Tulloch A. Characterizing wildlife behavioural responses to roads using integrated step selection analysis. J Appl Ecol. 2017;54:470-9.

52. Ranc N, Cagnacci F, Moorcroft P. Memory drives the formation of animal home ranges: evidence from a reintroduction. BioRxiv. 2020;32:693.

53. Ranc N, Moorcroft PR, Hansen KW, Ossi F, Sforna T, Ferraro E, Brugnoli A, Cagnacci F. Preference and familiarity mediate spatial responses of a large herbivore to experimental manipulation of resource availability. Sci Rep. 2020;10:11946

54. Ranc N, Moorcroft PR, Ossi F, Cagnacci F. Experimental evidence of memory-based foraging decisions in a large wild mammal. Proc Natl Acad Sci USA. 2021;118:e2014858118.

55. Rodriguez-Morales B, Diaz-Varela ER, Marey-Perez MF. Spatiotemporal analysis of vehicle collisions involving wild boar and roe deer in NW Spain. Accid Anal Prev. 2013;60:121-33.

56. Sawyer H, Kauffman M, Middleton AD, Morrison TA, Nielson RM, Wyckoff TB. A framework for understanding semi-permeable barrier effects on migratory ungulates. J Appl Ecol. 2013;50:68-78.

57. Sawyer H, Kauffman MJ. Stopover ecology of a migratory ungulate. J Anim Ecol. 2011;80:1078-87.

58. Sawyer H, Merkle JA, Middleton AD, Dwinnell SPH, Monteith KL. Migratory plasticity is not ubiquitous among large herbivores. J Anim Ecol. 2018. https://doi.org/10.1111/1365-2656.12926. 
59. Sawyer H, Middleton AD, Hayes MM, Kauffman M, Monteith KL. The extra mile: Ungulate migration distance alters the use of seasonal range and exposure to anthropogenic risk. Ecosphere. 2016. https://doi.org/10. 1002/ecs2.1534.

60. Seidler RG, Long RA, Berger J, Bergen S, Beckmann JP. Identifying impediments to long-distance mammal migrations. Conserv Biol. 2015;29:99-109.

61. Shepard DB, Kuhns AR, Dreslik MJ, Phillips CA. Roads as barriers to animal movement in fragmented landscapes. Anim Conserv. 2008;11:288-96.

62. Signer J. amt: animal movement tools. R package version 4. 2018

63. Singh N, Borger L, Dettki H, Bunnefeld N, Ericsson G. From migration to nomadism: movement variability in a northernungulate across its latitudinal range. Ecol Appl. 2012;22:2007-20.

64. Spitz DB, Hebblewhite M, Stephenson TR. 'MigrateR': extending modeldriven methods for classifying and quantifying animal movement behavior. Ecography. 2017:40:788-99.

65. Therneau TM. Package 'coxme': mixed effects cox models. R package version 2. 2015

66. Thompson PL, Gonzalez A. Dispersal governs the reorganization of ecological networks under environmental change. Nat Ecol Evol. 2017;1:162.

67. Thurfell H, Ciuti S, Boyce MS. Applications of step-selection functions in ecology and conservation. Mov Ecol. 2014;2:4.

68. Trombulak SC, Frissell CA. Review of ecological effects of roads on terrestrial and aquatic communities. Conserv Biol. 2000;14:18-30.

69. Tucker MA, Bohning-Gaese K, Fagan WF, Fryxell JM, van Moorter B, Alberts SC, Ali AH, Allen AM, Attias N, Avgar T, Bartlam-Brooks H, Bayarbaatar B,
Belant JL, Bertassoni A, Beyer D, Bidner L, van Beest FM, Blake S, Blaum N, Bracis C, Brown D, de Bruyn PJN, Cagnacci F, Calabrese JM, Camilo-Alves C, Chamaille-Jammes S, Chiaradia A, Davidson SC, Dennis T, Destefano S, Diefenbach D, Douglas-Hamilton I, Fennessy J, Fichtel C, Fiedler W, Fischer C, Fischhoff I, Fleming CH, Ford AT, Fritz SA, Gehr B, Goheen JR, Gurarie E, Hebblewhite M, Heurich M, Hewison AJM, Hof C, Hurme E, Isbell LA, Janssen R, Jeltsch F, Kaczensky P, Kane A, Kappeler PM, Kauffman M, Kays R, Kimuyu D, Koch F, Kranstauber B, Lapoint S, Leimgruber P, Linnell JDC, Lopez-Lopez P, Markham AC, Mattisson J, Medici EP, Mellone U, Merrill E, de Miranda-Mourao G, Morato RG, Morellet N, Morrison TA, Diaz-Munoz SL, Mysterud A, Nandintsetseg D, Nathan R, Niamir A, Odden J, O'Hara RB, Oliveira-Santos LGR, Olson KA, Patterson BD, Cunha de Paula R, Pedrotti L, Reineking B, Rimmler M, Rogers TL, Rolandsen CM, Rosenberry CS, Rubenstein DI, Safi K, Said S, Sapir N, Sawyer H, Schmidt NM, Selva N, Sergiel A, Shiilegdamba E, Silva JP, Singh N, et al. Moving in the Anthropocene: Global reductions in terrestrial mammalian movements. Science. 2018;359:466-9.

70. Zeller KA, McGarigal K, Beier P, Cushman SA, Vickers TW, Boyce WM. Sensitivity of landscape resistance estimates based on point selection functions to scale and behavioral state: pumas as a case study. Landsc Ecol. 2014;29:541-57.

\section{Publisher's Note}

Springer Nature remains neutral with regard to jurisdictional claims in published maps and institutional affiliations.
Ready to submit your research? Choose BMC and benefit from:

- fast, convenient online submission

- thorough peer review by experienced researchers in your field

- rapid publication on acceptance

- support for research data, including large and complex data types

- gold Open Access which fosters wider collaboration and increased citations

- maximum visibility for your research: over $100 \mathrm{M}$ website views per year

At BMC, research is always in progress.

Learn more biomedcentral.com/submissions 